\title{
Research Orientation Among Undergraduate Medical Students
}

\author{
Sabitha Vadakedath ${ }^{1}$, Venkataramana Kandi* \\ Date Of submission: 15-4-2021 \\ Date of Review: 22-4-2021 \\ Date of Acceptance : 28-4-2021 \\ 1. Department of Biochemistry, Prathima Institute of Medical Sciences, Karimnagar, India \\ 2. Department of Microbiology, Prathima Institute of Medical Sciences, Karimnagar, India \\ *Corresponding author: \\ Venkataramana Kandi Department of Microbiology, Prathima Institute of Medical Sciences, Karimnagar, INDIA \\ E MAIL: ramana20021@gmail.com \\ DOI: 10.47799/pimr.0901.02
}

\section{ABSTRACT:}

There is increased demand for doctors in India and elsewhere throughout the world. Considering this, the government of India has taken initiatives to increase the number of medical colleges, thereby produce enough medical graduates to cater to the ever-increasing population of the country. Also, there is a debate over the quality of medical education provided by medical institutions. Therefore, the National medical council (NMC), the statutory body instituted by the government of Indiafor governing medical practice and education, had taken several initiatives to improve the quality. One among them is the introduction of Medical Education Technology (MET) as a mandatory requirement for the teaching faculty. Another significant development in this direction is the change of curriculum that focuses more on the mandatorystudent's competencies in the patient management perspective. The new curriculum creates a space for students to perform research projects for a period of two months after the completion of the third year of study. We, therefore present a clear perspective on the teacher, learners' attitudes along with the overview of benefits and types of research.

KEYWORDS: doctors, medical graduates, medical institutions, curriculum, research, projects

\section{INTRODUCTION:}

Orientation is the attitude of a person towards a particular topic or an issue. The research is a never-ending process of studying and observing with prior knowledge. It generally involves working on a topic of interest that is aimed to draw a novel and an improved conclusion.

A teacher's role in a student's life is crucial because the attitudes of a teacher arecarried forward by the students in their life [1]. Thus, a teacher should be able to inculcate kindness, sensitivity, motivation, discipline, stability, and ethics in the life of young and budding students. It is the teacher who shapes the professional life of a student [2].
Attitudes of teachers

A teacher must havea positive approach in receiving the ideas of the aspiringstudents [3]. Whether the idea is worth it or not has to be revealed to the student in an appropriatemanner, thereby making them review their thought process. A sensible teacher makes wonders in the life of an upcoming student [4].

Negative attitudes of the teacherscause psychological disturbances in students and influence theiroverall performances[5]. It was concluded in a previous study that the use of humiliation, fear, and intimidation against students created shyness, anxiety, and habit disorders, which may finally lead to personality disorders in students[6]. The negative attitudes of the teacher, especially in elementary school children caused permanent effectson their whole life. This can be similar to post-traumatic stress disorder. The negative attitudes of teachersalso affect students physically as noted by the development of muscle cramps, stomachupset, among others[7].

A Teacher should compete with the student while acquiring knowledge but never a teacher is supposed to perceive his/her student as a competitor or obstacle for their career development. This competitive attitude of the teacher causes students to lose their research attitudes and further degrades the big built image of the teacher in the student's heart. An ideal teacher would invoke a research attitude in students' minds by showing applications of the topics they teach. This stimulates logical reasoning in the mind of students. Most importantly, thelectures have to be made lively, which may include sharing one's own real-life experiences[8].

A good teacher must appreciate the researchorientated thinking of students, guide them, and give them enough time to envisage research work. 
Among the various factors that contribute to ateacher's ability to cultivate research orientation in students include the teacher's hold on the language, his/her personality, listening abilities, valuing, fairness, encouragement, and adaptability. Other aspects includingteacher'smastery over the subject, self-belief (the belief that one is efficient and can produce desired results), empowerment (achieving selfassigned goals), accountability, and attitude towards research make them self-evaluate critically and can help to interpret the behavior of students[9].

The role of a teacher in a student's life takes its shape from school days onwards [10]. Because early in life, the attitude and practices of the teacher is the one which influences the development of students. Teachers must productively use the time in classrooms toensure that their studentsachieve deeper levels of understanding and metacognition (selfawareness and understanding one's thought process) [11].

Apart from the family members, the teacher is endowed with the personality development, academic and social performances of the students. The teacher's way of asking questions, understanding their thoughts, showing interest, and appreciation motivates them to try and achieve success.

A teacher with good communication skills and those having concern for their students will shape the student's psyche and prepare them to be considerate with others, help the needy, maintain good relations and positive attitudes towards people and life, respectively $[12,13]$.

In short, teachers are second only to parents in determining the personality development of students. Hence, teachers should keep this in mind irrespective of their working environments that include schools, colleges, and universities, etc. The teachers must never give unwanted stress to the students, that invariably damage them from the inside because as a student they spend most of their time with the teachers[1].

\section{Benefits of student's research interest}

The student's aptitude for research helps them to find and connect with the truth to practice. It increases and strengthens student's self-confidence and the thirst for knowledge in their respective areas of practice. The students learn to work as a team and while doing research they develop skills likecreativity, planning, utilization of time, boosts morale and motivation, fast learning capabilities, encourages to take healthy risks, and relieves stress.

The research interest among the students allows them to develop interpersonal skills like speaking and listening, which allows them to communicate well with the patients.Working in small groups enhances the process of discussion which makes them learn fast and increases subject retention rates And most importantly, the students improve on trust, commitment, accountability, focus, and conflict management[14].

\section{Research in academia}

Research is considered mostly as a mode ofcareer improvement or for promotion. Conversely, research is a continuous process that is generally undertaken by some academicians by interest. Unfortunately, people with research interestsareforced to suffer due to the selfish nature of either the corporate management, the behavior of colleagues,and the heads of the departments who create obstacles/hurdles for research activities. Mostresearch-oriented people are not supported, which invariablycauses them to lose their interest. Similarly, the student's research orientation is greatly influenced by theinstitute and the teachers.

Teacherscarryout research activities to enhance their salaries andtoget recognizedby the management of the institutes. They will not do research or apply it for the welfare of the student due to a lack of support from colleagues. In medicine, researchupdatesare used by physicians and surgeons to improve their skills andcareer development. The postgraduate studentscarryout time-bound research in their respective fields to earn the degree.

Currently, the student orientation towards research is in a doubtful environment. Although students get inspired by a few research inclined teachers, sustenance of interest can be greatly influenced by the student's self-motivation, and time management, among others [15].

Research is a creative work, and in most instances, research is carried out for the benefit/well-being of humans and not just for the sake of pride, monetary benefits, and promotions. There is an urgent need to inculcate research attitude among the students from childhood. Also, it is important to followa practically oriented method of teaching/ learningto increase the research aptitude among the students. This is achieved if the management of educational institutions change their perspective andrecognize the fact that education is not a business that aims to earn monetary benefits, rather it is a platform that generates innovations, inventions, discoveries that benefit mankind.

\section{A guide to research process}

Research can be defined as a process of systematic collection and documentation of data, analysis, and interpretation with suitable methodologies.

Benefits of student's research in the medical field include an improved understanding of clinical medicine, facilitates critical thinking and appraisal, improves future post- 
graduate studies, develop teamwork skills, and exposes them to the best clinical minds[16].

The importance of student's orientation towards research includes a positive inclination on working for the benefits of mankind without expecting monetary benefits, research experience before post-graduation contributes to an improved selection process of the area of specialization, and publications produced from the research will also increase the scope of future research. Therefore, it is essential to make student research mandatory atthe undergraduate level as a part ofthe medical curriculum[17].

Among the various types of research, the ones suitable for undergraduates include epidemiological studies, retrospective analyses, quality improvement (QI) studies, and translational research[18].

While planning research, the students at the undergraduate level must consider several factors that include time and corneringon to aspecific research question. The students can benefit from spending some time observing thecampus environment, and the patients while attending the clinical postingsin the hospital. Then dig on to what may be the probable reason for your research inclination and potential sources that may facilitate you to perform it.

Students should identify an appropriatepeer/ researcher with whom he/she wants to do research and consider him/her as a mentor/guide. Students must opt for a researcher who is polite, approachable, and who frankly shares his/her viewswithout any hesitation. Students may benefit from approachable seniors on the campus or college, who can guide them in the process of research.

Topic selection is crucial, and therefore, students must be cautious while selecting. Research topics thatare more interesting to you, the time factor, and the availability of sample/participants should be some of the criteria for topic selection.

\section{Observational/epidemiological studies}

Epidemiology deals with various factors that determine the presence or absence of a disease or a disorder in a population.It is a survey-based study wherein the answers from the people participating in the study are considered to assess the disease prevalence, predisposing, and other risk factors [19]. The major types of research studies aredelineated in Table 1.

\begin{tabular}{|c|l|l|}
\hline S.No. & \multicolumn{1}{|c|}{ Epidemiological study type } & \multicolumn{1}{|c|}{ Applications } \\
\hline 1 & Observational study & $\begin{array}{l}\text { Uses a predefined parameter, a group of predefined people, } \\
\text { limited time period, and assesses the exposure to risks affecting } \\
\text { the health. }\end{array}$ \\
\hline 2 & Cross-sectional study/survey & $\begin{array}{l}\text { Almost includes the entire population/random sample } \\
\text { representative group. } \\
\text { Uses questionnaire to collect the data in single contact. } \\
\text { Tries to find the cause of a disease or the potential risk factors. }\end{array}$ \\
\hline 3 & Case-control study & $\begin{array}{l}\text { Assesses the history of exposure to risks in cases and compares } \\
\text { them with the healthy controls with similar risk exposures, age, } \\
\text { sex, and other sociodemographic characters. }\end{array}$ \\
\hline 5 & $\begin{array}{l}\text { Cohort study } \\
\text { (longitudinal/prospective) }\end{array}$ & $\begin{array}{l}\text { Groups of individuals with different exposure levels to potential } \\
\text { risk factors. } \\
\text { Participants are observed over a long time (months-years). } \\
\text { Rates of disease/condition with respect to the exposure to risk } \\
\text { factors is calculated }\end{array}$ \\
\hline
\end{tabular}




\section{Table 1: Types of research studies and their applications}

\section{Cohort studies}

Cohort studies are a type of panel/group study where the individuals in the panel have a common characteristic at a particular time. For example, the study participants may be suffering from the disease at a given time. The cohort studies are often used to obtain evidence between the cause and outcome of a disease or disorder[20]. The cohort studies may be either prospective(used in drug development studies wherein a defined age group people are given a drug and its side-effects are noticed and followed by treatment to relieve side effects) or retrospective (looking back in time E.g.: medical records). Prospective cohort studies give more reliable results than retrospective ones. The advantage of cohort studies includesmultiple outcomes associated with a single exposure, and the long follow-up periods, increased costs are some disadvantages [21].

The plan for conducting a cohort study is shown in Figure 1.F

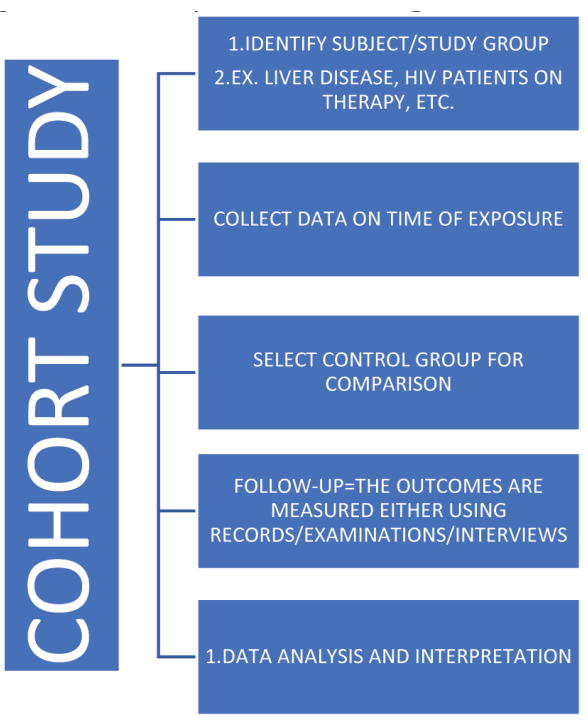

Figure 1: Workflow of cohort studies

\section{Case control studies}

These are a type of observational studies, where there is a comparison with a group having a particular disease and agroup comprising of healthy individuals [22]. Case-control studies are used to study rare diseases and are mostly retrospective in nature. These studies help to determine the association between exposure and specific health conditions/ disease. The case-control studies proceed from the effect/ outcome to the cause [23,24]. The advantages of case-control studies include quick, inexpensive, easy to perform, help in the investigation of outbreaks, and the study of rare diseases. The disadvantages are the difficulty in selecting the control group, and the potential bias associated with the observations made on the cause and the effect at the same time.
The research process of a case control study is shown in Figure 2.

\begin{tabular}{ll}
\hline CASE- & ENROLLMENT OF THE \\
CONTROL & $\begin{array}{l}\text { CASE AND CONTROL } \\
\text { GROUP }\end{array}$ \\
STUDY & $\begin{array}{l}\text { COLLETION OF DATA FROM } \\
\text { BOTH THE GROUPS }\end{array}$ \\
EX. HDL & \\
CHOLESTEROL & ANALYSIS, COMPARISON, \\
IN PSORIASIS & $\begin{array}{l}\text { AND INTERPRETATION OF } \\
\text { DATA }\end{array}$
\end{tabular}

\section{Figure 2: Workflow of case-control studies}

\section{Cross sectional studies}

The cross-sectional studies are also called prevalence or transverse studies. These are observational, where the data is collected, analyzed, and compared at a specifictime in a different population group[25]. The cross-sectional studies show the association between two variables withthe prevalence of illness in a population andhelp in testing thescientific hypothesis.

The advantages of cross-sectional studies include low cost, takes less time for completion, and the data collected can be used for other studies. The disadvantages include the confirmation of the cause and effect, and the false answers to questions during a survey/interviewgeneratesa bias in the study.

The research process in a cross-sectional study is depicted in Figure 3.

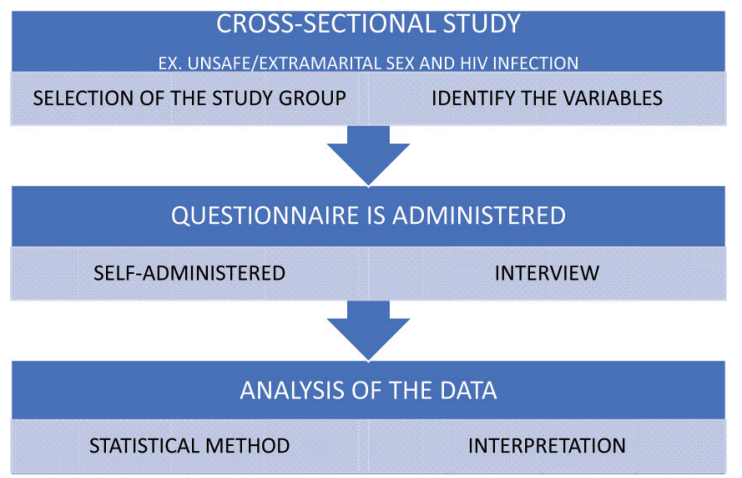

Figure 3: Workflow of cross-sectional studies

\section{Interventional studies/experimental studies/clinical trials}

Interventional studies are also called experimental studies[26]. These studies are generally referred to as clinical trial studies. In such studies, the device, test, or treatment given to people is assessed for their potential beneficial effects. The clinical trials help us to know whether the new drug ormedical device or vaccine or a specific supplemental diet is safe and effective in humans [27]. There are five phases of clinical trials as delineated in Table 2. 


\begin{tabular}{|c|l|l|l|}
\hline S.No. & \multicolumn{1}{|c|}{$\begin{array}{c}\text { Phase of } \\
\text { clinical trial }\end{array}$} & Type of study & Nature of study \\
\hline 1 & $\begin{array}{l}\text { Phase 0/ } \\
\text { Micro dosing }\end{array}$ & Exploratory & $\begin{array}{l}\text { Examines too low concentrations (micro dosing) of drug for less time is } \\
\text { tested in 10-20 subjects,to study the pharmacokinetics and to } \\
\text { determine the dose for phase I studies, and these are presently done } \\
\text { in animals and future human micro dosing studies are expected }\end{array}$ \\
\hline 2 & Phase I & $\begin{array}{l}\text { Non-therapeutic } \\
\text { trial }\end{array}$ & $\begin{array}{l}\text { Around 20-50 healthy subjects are recruited. } \\
\text { Establishes safe dose range, the maximum tolerated dose and examines } \\
\text { the pharmacokinetic and pharmacodynamic effects, and these are } \\
\text { generallysingle centre studies }\end{array}$ \\
\hline 3 & Phase II & Exploratory & $\begin{array}{l}\text { Recruiting around 5-100 patients of either sex. } \\
\text { Examines the effective dosage and the therapeutic effects in patients, } \\
\text { helps to decides the therapeutic regimen, drug-drug interactions, and } \\
\text { these are generally, multicentre studies }\end{array}$ \\
\hline 4 & Phase III & $\begin{array}{l}\text { Therapeutic } \\
\text { confirmatory trial }\end{array}$ & $\begin{array}{l}\text { More than 300 patients of either sex are recruited in this study, it } \\
\text { examines the efficacy and the safety of the drug, used to comparethe } \\
\text { test drug with the placebo/standard drug, and note down adverse drug } \\
\text { reactions/adverse events }\end{array}$ \\
\hline 5 & Phase IV & $\begin{array}{l}\text { Post-approval } \\
\text { study }\end{array}$ & $\begin{array}{l}\text { After approval/post-licensure and post-marketing studies, following up } \\
\text { of the patients for a very long time for potential adverse reactions and } \\
\text { drug-drug interactions }\end{array}$ \\
\hline
\end{tabular}

\section{Table 2: The phases of clinical trials}

The major disadvantages of clinical trials include difficultyin interpreting the results, the increased risk associated with the novel drug, and the long-time intervals associated with the clinical study. The clinical trial study process is depicted in Figure 4.

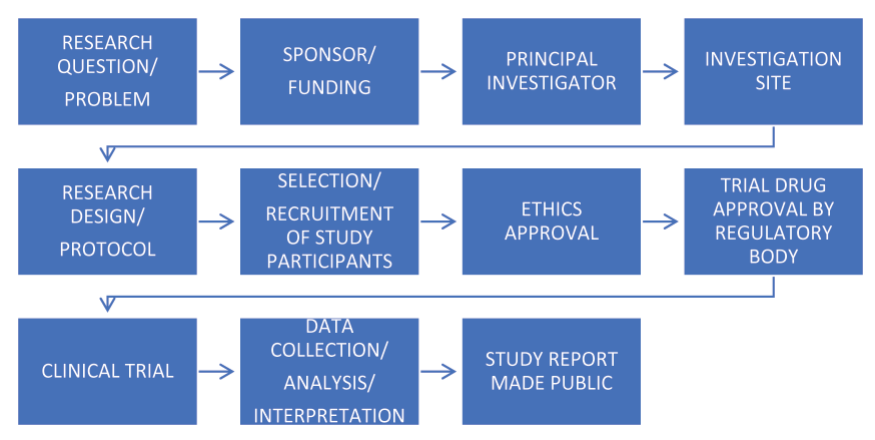

Figure 4: Workflow of a clinical trial study

Clinical research could be prospective or retrospective. It may also be a case-control study or a cohort study. Clinical trials may be initiated to find treatment, to prevent, to observe, and to diagnose a disease or a medical condition. The clinical trial studies are regulated nationally, and internationally by the respective agencies like the Indian Council of Medical Research (ICMR), and the Drug Controller General of India (DCGI) in India, and the Food and Drug Administration (FDA) of the United States of America (USA).
The principal guidelines of clinical research adhere to good clinical practices (GCPs), good manufacturing practices (GMP), and good laboratory practices (GLP) as proposed by the international conference of harmonization (ICH), Council for International Organizations of Medical Sciences (CIOMS), and the World Health Organization (WHO) [28].

\section{The retrospective studies}

These types of studies usethe data that has been collected and stored in the form of medical records. Such studies are performed to find the relationship between exposures, suspected risk factors, and othercontributing elements that may be associated with a particular disease.

The retrospective studies involve the collection of the samples and preserved information about past events associated with patients. In these studies, the history of patients is used to find associated risk factors for a disease/medical condition. Most cohort studies are retrospective ones. Retrospective studies help the researchers to investigate the rare outcomes of human diseases and can quickly estimate the results of exposure and obtaining a preliminary measure of the association where prospective studiesare not possible [29].

Disease surveillance, the evolution of disease as well as the impact of treatment on survival and disease progression, comparisons of treatment modalities where clinical trials are 
not possible, changing strategies of therapy according to predicted risk factors of a particular disease, inexpensive and fast, and helps in constructing future prospective study designs are among the various uses, and advantages of retrospective studies. The disadvantages of retrospective studies include the potential poor quality and the absence of important factors contributing to disease in stored data[30].

The research process while conducting a retrospective analysis is depicted in Figure $\mathbf{5}$.
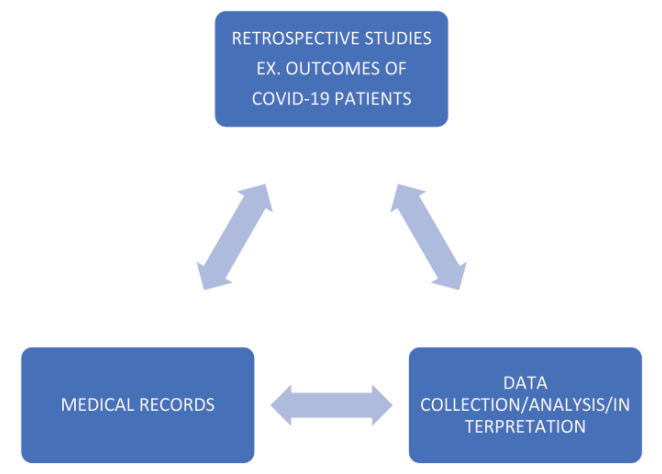

Figure 5: Workflow of retrospective studies

\section{Quality improvement (QI) initiative research}

The QI initiatives are the activities undertaken to improve an organization's operations and finances for the maintenance of the quality of the health care system[31]. It is achieved by evaluating and learning from past experiences [32]. The four key components of QI are problem, goal, aim, and measures as shown in Figure 6.

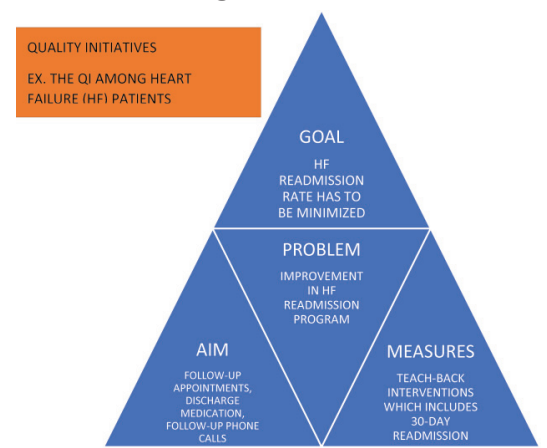

Figure 6: Workflow of quality initiative (QI) studies

\section{Problem}

Identify the problem and get an in-depth understanding of the problem. Here you have to define the quality improvement policy to the target problem.

\section{Goal}

Selecting a goal for quality improvement is a challenging task and it should be based on the return of investment. The goal must have benefits both for organization as well as patients.

Aim

It helps the researcher to break the goal into manageable pieces for achievement.

\section{Measures}

The measure for $\mathrm{QI}$ can be initiated by performingan in-depth study of the results. The goalof $Q$ I is taken whether it is benefitting the patients and improving the organization's reputation has to be studied thoroughly to take appropriate measures of QI.

The keys for QI successliesinthe adaptive leadership (the data drove QI process), analysis (checking whether goals are implemented), evidence-based practices to reach QI, adoption for delivery of quality affordable care, and financial management to avoid unnecessary wastage of resources [33].

The advantages of QI studies include quality improvement both for patient and management, improves the non-participant attitude of employers giving success, growth, and advancement to the organization, and helps in decreasing the waste and improving productivity and profitability to the organization. The QI studies also help the organizations to achieve the potential for market competition andimprove communication[34].

The disadvantages of such studies include the requirement of extensive training of the employees, resistance by the employees to quality improvement programs which can lower their morale and affect the productivity of the organization. Also, the QIs discourage creativity and innovationand the organization has to spend extensively for training, team development, and infrastructure.

The essential elements of a QI research program include thinking differently (traditional quality control program has a loophole and there is a possibility of quality decline) systematic approach (clarity of goal, and planning accordingly), focused (clear vision and objective in such a way that everyone understands), Identification of supporting staff for the project (a team comprising sincere workers), time-bound (the team should be aware of acquisition of new skills in a short time), evaluation (transparent self-evaluation on improvement), documentation of results, and sustainability[35].

\section{Translational research}

This type of research translates fundamental research into medical practice and generates meaningful health benefits[36].The product of translational research provides a new treatment that can be practically used either by clinicians or can be commercialized [37].It takes a long period of time to 
bring a change in the treatment plan, and hence, a dedicated department for research or designated research institutes can undertake this type of research[38].

The advantages of translational research include the potential of basic science advances becoming real-world benefits to people. The translational research helps in decreasing the time spent on pre-clinical trial studiesinvolving a novel drug candidate (compound) as it gathers informationon basic research results related to that compound[39]. The disadvantages of translational researcharethe lack of credit given for basic science research and the possibility of missing rare side effects while using the new method or compound in the treatment process[40]

The translational research has two stages referred to as the T1 stage, and T2 stage. The T1 stagetranslates from bench to bedside and includes the completion of preclinical studies and the development of clinical trial protocols. The T2 stage translates from bedside to community and it includes the adoption of new therapies and practices in the clinics of the community [41].The process involved in translational research is depicted in Figure 7.

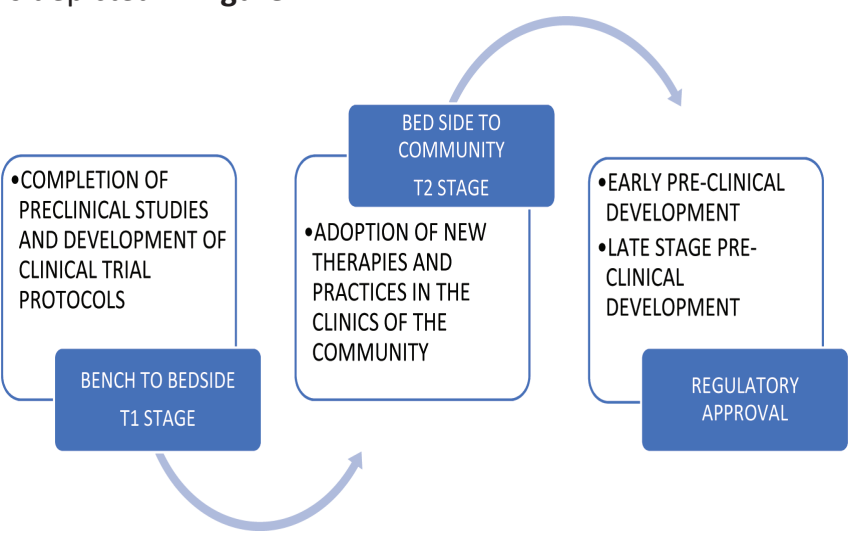

\section{Figure 7: Workflow of translational studies}

The early pre-clinical development involves assessment of formulas used for new drug development, planning testing strategies, and development of a protocol for theinvestigation new drug (IND) process is initiated.

In the late pre-clinical stage, the new drug is manufactured based on the formulas developed in the early preclinical stage. Also, at this stage, the study protocol is finalized, pharmacological and toxicological studies are conducted, and the application for an investigational new drug (IND)is submitted to FDA [42].

The FDA reviews the IND application for a month (30 days). In cases where the clinical trial issues are noticed by the authorities, the FDA holds the decision of approval[43, 44]. Once the issues are resolved, and in cases where there are no objections, the manufacturer gets FDA approval.
Case studies, literature reviews, systematic reviews, and meta-analyses

Because of several constraints associated with performing research work by the medical undergraduate students that include funding, time constraints, and others, we recommend other alternative methods to pursue research by medical students. These include writing a case report, case series, performing extensive literature surveys, and write literature reviews. Also, a medical undergraduate can take-up writing systematic reviews, and meta-analyses which are considered equal to doing original research.

The case study may include a description of a rare disease, observation of an uncommon clinical entity in otherwise common disease, and many other unusual findings that may be noted by the physicians/surgeons as a part of patient management $[45,46]$.

The literature reviews are written in a focused area highlighting the current and previous research findings and delineating potentially significant flaws and the areas of improvement that require further research studies. Literature reviews are highly cited research pieces that are generally written by experts in their respective fields. Nevertheless, medical graduates can identify their area of interest and can try writing small (mini-review) and extensive literature reviews (full-review).

The systematic reviews and meta-analyses that give the researchers credit on par with the original research follow almost the same procedures as done when a researcher attempts to perform original research work. Here, the researchers must identify a core area and write down the study protocol which contains a clear research question, and predefined methods (data collection repositories, studies inclusion, and exclusion criteria) that are reproducible. The researchers collect the data, analyze, and interpret the results, thereby making significant recommendations on an important aspect related to patient management.

The meta-analyses follow the same process as the systematic reviews but include the application of statistica methods for quantification of the data collected and to assess the statistical significance. Both the systematic reviews and meta-analyses minimize the selection bias and therefore are considered highly beneficial, especially while evaluating the data on drugs/treatments that are used for the management of diseases like cancer, Coronavirus disease-19 (COVID-19), and others [47].

The scoping reviews are a novel type of reviews that investigate the associations or present potential evidence of the associations. They may be considered as precursors for future research and can be supported by systematic analyses [48]. The types of reviews, their process, the potential for bias, and applicationsare shown in Figure 8. 


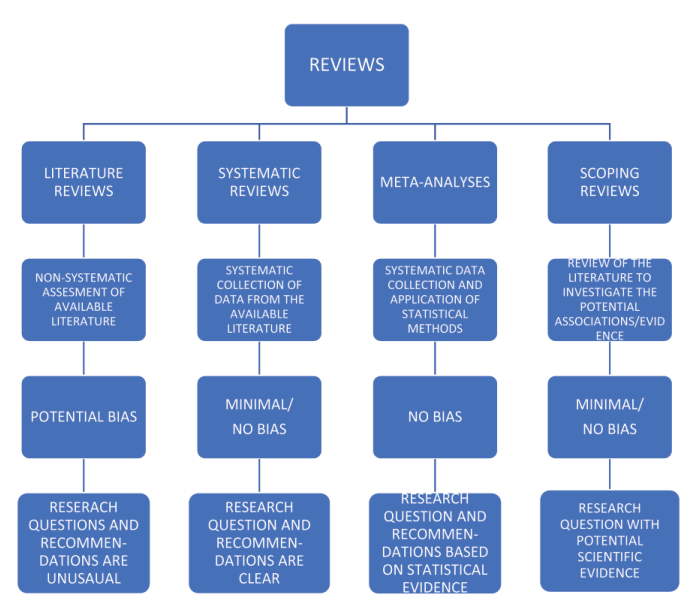

Figure 8: Types of review studies

\section{Conclusion}

Research is a part and parcel of education. The medical education prepares an individual to efficiently manage and treat patients. Learning is a continuous and life-long process wherein the individuals acquire knowledge and regularly update themselves with latest developments. Research in medical education would contribute to improved understanding of the subjects and potentially inculcate investigative abilities among students. This could pave the way for medical inventions and discoveries that invariably benefit public health.

\section{REFERENCES}

1. Ulug M, Ozden MS, Eryilmaz A. The Effects of Teachers' Attitudes on Students' Personality and Performance. Procedia - Social and Behavioral Sciences 2011;30: 738742. https://doi.org/10.1016/j.sbspro.2011.10.144.

2. Lieberman, A. (1996). Practices that support teacher development. Transforming conceptions of professional learning. In M. W. McLaughlin, \& I. Oberman (Eds.), Teacher learning: New policies, new practices (pp. 185201). New York: Teachers College Press.

3. Ramana KV. Mindset in medical teaching and learning. J Contemp Med Edu. 2015; 3(1): 1-1. doi:10.5455/ jcme.20150326042633

4. P. Prokop et al. The role of teacher in students' attitudes to and achievement in palaeontology EEST Part B Social and Educational Studies 3 ;2011: 29-45

5. Gecer, A.K. Ogretmenyakinligininogrencilerinbasarilari, tutumlarivegudulenmeduzeyleriuzerindekietkisi. The effect of teacher immediacy on students' performance, attitude and motivation). Unpublished doctoral dissertation, University of Ankara, Ankara. 2002.
6. Adams, N. A., \& Holcomb, W. R. Analysis of the relationship between anxiety about mathematics and performance. Psychological Reports. 1986; 59; 943-948.

7. Meece, J. L., Wigfield, A., \& Eccles, J. S. Predictors of math anxiety and its influence on young adolescents' course enrollment intentions and performance in mathematics. Journal of Educational Psychology. 1990; 82, 60-70.

8. Inelmen, E. Integrating all learning activities around a city study curriculum. Cypriot Journal Of Educational Sciences. 2011;6(1): 37-45

9. Ataunal, A..Nicinvenasilbirogretmen? Why and what kind of a teacher?. Ankara: Milli EgitimVakfiYayinlari.2003:No. 4

10. Kwakman K. Factors affecting teachers' participation in professional learning activities Teaching and Teacher Education 2003; 19: 149-170 doi:10.1016/S0742051X(02)00101-4

11. Can, G. Kisilikgelisimi (Development of personality). B. Yesilyaprak. Egitimpsikolojisi: Gelisim-ogrenme-ogretim. Educational psychology: Development-learning-teaching. 2011:7th Ed. 119-151. Ankara: PegemAkademi

12. Ramana KV, Kandi S, Boinpally PR. Ethics in medical education, practice, and research: An insight. Ann Trop Med Public Health 2013; 6:599-602

13. Kandi V. Patient safety: a developing world perspective. Appl Med Res. 2015; 1(3): 89-89. doi:10.5455/ amr.20150501120912

14. Russell, S. H., Hancock, M. P., \& McCullough, J. (2007). Benefits of undergraduate research experiences. Science. 2007; 316, 548-549.

15. H. Johnson Nenty. Research Orientation and ResearchRelated Behaviour of Graduate Education Students. Journal of Social Sciences. 2009;19:1, 9-17, DOI: 10.1080/ 09718923.2009.11892685

16. Petrella JK, Jung AP. Undergraduate Research: Importance, Benefits, and Challenges. Int J Exerc Sci. 2008;1(3):91-95. Published 2008 Jul 15.

17. Metcalfe D. Involving medical students in research. J R Soc Med. 2008;101(3):102-103. doi:10.1258/ jrsm.2008.070393

18. Röhrig B, du Prel JB, Wachtlin D, Blettner M. Types of study in medical research: part 3 of a series on evaluation of scientific publications. DtschArztebl Int. 2009 Apr;106(15):262-8. doi: 10.3238/arztebl.2009.0262. Epub 2009 Apr 10. PMID: 19547627; PMCID: PMC2689572. 
19. Morris JN. Uses of epidemiology. Edinburgh: Livingstone; 1957.

20. Kannel, W. B., Dawber, T. R., Kagan, A., Revotskie, N., Stokes, J,III. Factors of risk in the development of coronary heart disease--six year follow-up experience: the Framingham study. Ann. Intern. Med. 1961; 55: 33-50.

21. Colditz GA, Manson JE, Hankinson SE. The Nurses' Health Study: 20-year contribution to the understanding of health among women. J Women's Health 1997;49-62.

22. Morabia A. A History of Epidemiologic Methods and Concepts. Birkhaeuser Verlag; Basel: 2004. pp. 1-405. [Google Scholar] [Ref list]

23. Cole P. The evolving case-control study. J Chronic Dis. 1979; 32(1-2):15-27.

24. Sudhakar T, Sabitha V, Raj Kumar G, Jhansi Rani C, Pratyusha P, Kandi V. (2018) Evaluation of Serum Electrolytes among Psoriasis Patients: A Prospective CaseControl Study from Telangana, South India. Biochem Anal Biochem 7: 365 . doi: 10.4172/21611009.1000365Hennekens $\mathrm{CH}$, Buring JE. Epidemiology in Medicine, Lippincott Williams \& Wilkins, 1987.

25. Rothman KJ, Greenland S, Lash TL. Modern epidemiology. Wolters Kluwer Health; 2008. [Google Scholar] [Ref list]

26. "Clinical Trials" (PDF). Bill and Melinda Gates Foundation. Retrieved 1 January 2014

27. "What are the different types of clinical research?". US Food and Drug Administration. 2019. Retrieved 24 May 2019

28. ICH Guideline for Good Clinical Practice: Consolidated Guidance Archived 21 September 2008 at the Wayback Machine

29. "Prospective vs. Retrospective Studies". StatsDirect. StatsDirect. Retrieved 2 August 2017

30. Hyde, James N. "Retrospective Cohort Study: Strengths and Weaknesses". Tufts Open Courseware. Tufts University. Archived from the original on 12 May 2017. Retrieved 2 August 2017.

31. Batalden PB, Davidoff F. What is "quality improvement" and how can it transform healthcare?.Qual Saf Health Care. 2007 Feb; 16(1):2-3.

32. Leslie Falk, Ann Tinker. The top five essentials for quality improvement in health care. Health Catalyst. 2017.www.healthcatalyst.com
33. Kaplan HC, Brady PW, Dritz MC, et al. The influence of context on quality improvement success in health care: a systematic review of the literature. Milbank $Q$. 2010;88(4):500-559. doi:10.1111/j.14680009.2010.00611.x

34. Baily MA, Bottrell M.M, Lynn J \& Jennings B. Special reports: The ethics of using QI methods to improve health care quality and safety. (1551-146X). Retrieved from http:/ /www.thehastingscenter.org/WP-content/Uploads?TheEthics_Of Using-QI-Methods.pdf

35. Relias Media. 9 steps used in quality improvement. December 1, 1997.http://www.reliasmedia.com/article.

36. Akarowhe K. Translational Research: Definitions and Relevance. J Biol Med Res. 2018;(2):2:13.

37. Woolf SH. The meaning of translational research and why it matters. JAMA. 2008;(2):211-3. Doi:10.1001/ jama.2007.26.

38. What is Translational Science.tuftstsi.org. Tufts Clinical and Translational Science Institute. Retrieved 2015.

39. Ashutosh Jogalekar (November 26, 2012). "The perils of translational research". Scientific American Blog Network.

40. Prinz F, Schlange T, Asadullah K (August 2011). "Believe it or not: how much can we rely on published data on potential drug targets?". Nature Reviews. Drug Discovery. 10 (9): 712. doi:10.1038/nrd3439-c1

41. Waldman, Scott A.; Terzic, Andre (2010-10-01). "Clinical and Translational Science: From Bench-Bedside to Global Village". Clinical and Translational Science. 3 (5): 254-257. doi:10.1111/j.1752-8062.2010.00227.x.

42. "Development \& Approval Process (Drugs)". U.S. Food and Drug Administration. Retrieved 22 May 2018

43. "Information Sheet Guidance For IRBs, Clinical Investigators, and Sponsors: FDA Inspections of Clinical Investigators" (PDF). June 2010. Retrieved 16 October 2014

44. Guidance for Industry: Financial Disclosure by Clinical Investigators, Food and Drug Administration, 20 March 2001

45. Ramana, KV. "Case Report Communications to a Scientific Journal: An Insight." American Journal of Medical Case Reports 1.1 (2013): 1-2

46. Kandi V, Koka S, Bhoomigari M (January 01, 2019) Hymenolepiasis in a Pregnant Woman: A Case Report of Hymenolepis nana Infection .Cureus 11(1): e3810. doi:10.7759/cureus.3810 
47. Uman LS. Systematic reviews and meta-analyses. J Can Acad Child Adolesc Psychiatry. 2011;20(1):57-59.

48. Munn, Z., Peters, M.D.J., Stern, C. et al. Systematic review or scoping review? Guidance for authors when choosing between a systematic or scoping review approach. BMC Med Res Methodol 18, 143 (2018). https://doi.org/ 10.1186/s12874-018-0611-x

How to cite this article : Vadakedath $S$, Kandi V. Research Orientation Among Undergraduate Medical Students. Perspectives in Medical Research 2021; 9 (1):2-11

DOI: 10.47799/pimr.0901.02

Sources of Support: Nil, Conflict of interest: None declared 